\title{
The Technology of Competencies Acquisition by Bachelors in Higher Education Institutions in the Conditions of the Digital Media Communication Environment
}

\author{
Ilona Batsurovska ${ }^{1}$ Nataliia Dotsenko ${ }^{1, *}$ Olena Gorbenko ${ }^{1}$ Nataliia Kim ${ }^{1}$ \\ ${ }^{I}$ Mykolayiv National Agrarian University, Ukraine \\ "Corresponding author.Email: dotsenkona@outlook.com
}

\begin{abstract}
This paper describes the technology of competencies acquisition by bachelors in higher education institutions in the conditions of the digital media communication environment. The use of media communication technologies requires an adequate level of acquisition of professional competencies by higher education applicants. The services that can be obtained in the process of preparation of higher education applicants through LMS based digital platforms + Office 365 are considered. The results provided an opportunity to outline digital media communication technologies for the acquisition of professional competencies by higher education applicants based on the use of the modern educational platform Cloud365 and the logical and harmonious combination of LMS + Office 365, which provides for the integration of modern systems, interactive tools, video and audio training. The technology of creation of the repository of competencies, the system of their coding and the leading principles of the development of a set of tasks for forming the professional competences of bachelors in the field of electrical engineering are considered. The effectiveness of the proposed technology was tested using the KolmogorovSmirnov statistical criterion.
\end{abstract}

Keywords: competency, bachelors, higher education institutions, digital media communication environment.

\section{INTRODUCTION}

\subsection{Problem statement}

The introduction of the digital market is crucial in today's world. In the context of the development of media communication technologies, investment in infrastructure, including $5 \mathrm{G}$, as well as in artificial intelligence and supercomputers, is increasing in everyday life. In modern world the most actual tendencies: full automation of technological processes, forecasting of development of a situation on the basis of accumulation of large volumes of data. Due to this, modern higher education applicants must have a basis of theoretical knowledge, be able to operate modern digital media communication technologies, use the advanced achievements of studying in the conditions of the digital learning environment. The content of education at universities is conditioned, on the one hand, by the globalization processes of the world, and on the other - by the emergence of new technologies in the professional education. The purpose of this study was to identify and validate technology for the acquisition of professional competencies by higher education in a digital space. Digitization of studying involves, in contrast to computerization, not only the use of media communication content of the learning environment for the formation of competencies, but also the digitalization of the processes of its formation and monitoring. This task is actualized not only by global transformation challenges, but also by the realities of modernity - the transition of free economic education to distance learning in a pandemic.

The educational standards are based on a competency-based approach and share a concept defining the requirements for a specialist, which is the basis of the Bologna process, and International Project 
of the European Commission 'Harmonization of educational structures in Europe' (Tuning Educational Structures in Europe, TUNING) [1], [2]. Within the framework of integration into the world educational space, the orientation of the curricula of students on the competence approach is relevant. Problems related to competency-based education are studied by wellknown international organizations: UNESCO [3], European Commission [4], Council of Europe [5], etc. In modern conditions of information society development, there is a need to develop such technology for the training of higher education applicants, which would provide opportunities to acquire professional competencies in the digital media communication environment.

\subsection{Analysis of recent research and publications}

Modern learning environments have the advantage of facilitating the learning process through offering materials and enabling the share of information. I. Blau, T. Shamir-Inbal, O. Avdiel confirmed that while the wide expansion of digital technologies in higher education has introduced the need for an examination of various technological tools for quality teaching and active individual and collaborative learning [6]. I. Grosemans, L. Coertjens, E. Kyndt note that it is important that students' educational background must be in congruence with their professional context [7].

There are investigations in the field of using digital media in learning environment. S. Schneider, M. Beege, S. Nebel, G.D. Rey investigated the using media in learning [8]. S. Manca made a conclusion that commercial social media are being increasingly adopted in formal learning settings even though they have not been conceived specifically for education [9]. O. Kuzminska, M. Mazorchuk, N. Morze, O. Kobylin of using informational and educational environment take into account the monitoring the attitude of tutors and students [10] and evaluation of students results but the modern education also takes into account a competency-based approach. M. Plenkovic and D. Mustic observe modern media communication and visual digitalization, not only in technical sense, but also, simultaneous development of digital culture and adaptation of media content, media production and distribution of content to the new web environment [11]. K. Baranidharan and K. Saravanan report that people use certain communication and educational channels to fulfil needs of students [12].

Also it was researched the competences acquisition in the learning environment. J. Strijbos,
N. Engels, K. Struyven mentioned that the need for deep understanding and univocal interpretation of intended generic and specific competences by teaching staff cannot be underestimated when it comes to quality outcome assessment [13]. A-E. GuerreroRoldan, I. Noguera describe the using of a competence approach in the conditions of informational and educational environment, it is useful for helping students attain the desired competence levels [14]. The findings of $\mathrm{Y}$. Chua, Z. Don provide supportive evidence for the validity of computer-based test in educational assessment [15]. Thus I. Arnold considered that online testing has become a common way to organize formative assessment in higher education [16]. J. Portilla, A. Varona, N. Otegi mentioned that graduate programs have to organize the activities building evidence of the achievement in acquiring such skills and competences [17]. So, testing is used for monitoring, but other measures are needed for the formation of competencies.

There are findings in the field of using media in the training of higher education applicants. The antecedents of attitude towards social media-based collaborative learning are explored by S. Molinillo, R. Anaya-Sánchez, R. Aguilar-Illescas, M. VallespínArán [18]. The importance of social support perceptions for college adjustment is detailed and the ramifications of the social media intervention are discussed by D. C. DeAndrea, N. B. Ellison, R. LaRose, C. Steinfield, A. Fiore [19]. D. Westerman, E. S. Daniel, N. D. Bowman outlined that students report positive attitudes toward social media [20]. M. Gawrycka, J. Kujawska, M. Tomchak examined the opinions of students and graduates of the faculty of economics of a technical university as regards their self-assessment of their preparation for entering the modern labour market. All the respondents participated during their studies in didactic projects aimed at improving their competencies taking into account the expectations of potential employers [21]. The social media use is still rather limited and restricted and that the variable most associated with frequency of use is scientific discipline, the study of S. Manca, M. Ranieri emphasises a generally more favourable attitude towards personal sharing and connecting with peers in professional networks rather than integrating these devices into their teaching practices [22]. J. Waycott, C. Thompson, J. Sheard, R. Clerehan remark that the students experienced benefits, such as being part of a cohesive learning community, but also felt conflicted about how much of their work and themselves they wanted to share [23]. It was considered the technology of competences acquirement for the higher education 
applicants of specialty 'Agricultural engineering' in the conditions of information and educational environment [24] by V. Oliynik, O. Samoylenko, I. Batsurovska, N. Dotsenko. But the technology of competencies acquisition by Bachelors in higher education institutions in the conditions of the digital environment media communication was not the subject of a special study.

Given the above, the aim of the paper is to present the technology of competencies acquisition by Bachelors in higher education institutions in the conditions of the digital media communication environment.

\section{THE TECHNOLOGY OF COMPETENCIES ACQUISITION IN THE CONDITIONS OF DIGITAL MEDIA COMMUNICATION ENVIRONMENT}

The digital media communication environment is an educational environment that is filled with digitized multimedia content and provides media communication as a feedback loop. Digital media communications are based on computer technology; they are flexible, hybrid; they have interactive potential; perform both private and public functions; characterized by a low degree of regulation; they are internally integrated, non-localized and ubiquitous. They have access to other communications and are an environment for both mass and individual communication. Media communications of the digital environment take into account the peculiarities of media culture and media communication. In order to acquire competencies in the chosen specialty, using media communications in a digital environment, it is necessary to follow some guidelines, for example to prepare for each media meeting both externally and psychologically and to consider the position of the workplace between the camera and the face of the interlocutor should be sufficient light. It is advisable to follow the business style of clothing during the reports. The report should be prepared in advance and carefully considered. Clear pronunciation of words, logical construction of sentences and concise construction of your own story will give the opportunity to form a good impression during media communication. Taking into account such features is able to form competencies in a digital media communication environment. There is a need to provide a number of recommendations for investigating, understanding, and designing educational curricula and activities that support the development of social media literacy [25]. However, other factors such as 'interactivity' and 'representational fidelity' are significant factors that predict flow in learning through virtual worlds [26]. As a result of the digitalization of education in European countries, the training system will be closely linked to those companies that will define professional standards and professional competencies.

The main resource of digital media communication education is information. The digitalization of education is changing the traditional education system in the direction of forming its new quality. This is reflected in the following [27]: the number of virtual educational platforms is increasing; one electronic resource can be used many times to provide different educational services; implementation of new technologies in education and digital media communication educational platforms which provide services. One of the main objectives of the European Union Framework Program [28] is to identify the key competences needed for employment, enhancement of personal potential, active citizenship and social integration. These highlighted the need to support efforts at European, national, regional and local levels to promote lifelong learning competences.

In the context of technological progress, a competence approach in the education of higher education applicants should be implemented through three aspects: development and introduction of modern educational standards into pedagogical practice of preparation of future specialists; training of higher education applicants by means of digital media communication technologies; organization of valid, objective and reliable control of quality of the competencies in the digital space. The goals of creating and using the digital space are to support and develop both the basic learning process and distance learning technologies, and the creation of a tool for planning, and organizing works to improve the educational and methodological base of educational institutions.

Technology of the development of the Cloud365 digital platform based on LMS + Office 365 involves the integration of modern systems, interactive tools, training simulators, video content and educational audio (Fig. 1).

The proposed integration of the Cloud365 digital technology with the LMS + Office 365 system can complement the process of full-time education of higher education applicants, as well as be used for the distance training stages. The web resources of the university have the following blocks: information blocks in the disciplines; consulting units for applicants and lecturers through thematic forums, chats and e-mail; block of presentation of educational information in text, audiovisual, graphic form, in the 
form of selection of hyperlinks; controlling and analytical units of digital media communication technology acquisition of professional competencies.

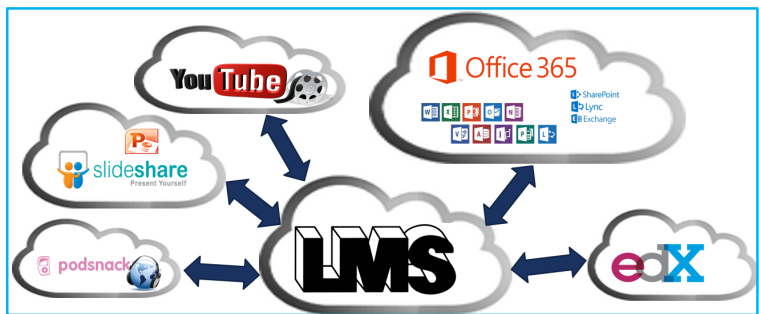

Figure 1 System of Integration of LMS + Office 365

It is analysed how competencies are acquired in the digital educational space. Thus, when designing a digital educational space, it is necessary to select educational tasks in such a way that they are able to form appropriate competencies among the higher education applicants. The implementation of the digital media communication technology of acquiring professional competencies of higher education applicants is based on three fundamental aspects:

1. Creating a repository of professional competencies in the digital Cloud365 space. The competencies are taken from the approved standards.

2. Binding of professional competencies embedded in the repository to tasks in the digital educational space. After forming a repository of competences in the online-digital educational space, creating a course task, it is necessary to determine what competences or their components the proposed task can form. Technologically, the relevant competence or individual component is selected and assigned to the course objectives, in the digital educational space.

3. Monitoring the acquisition of professional competencies by higher education applicants by the tools of digital media communication environment: assessment in a digital environment, commenting on a Slideshare, interactive tasks.

To create a repository in the digital educational space, it is necessary to create a corresponding curriculum template, specifying its repository, category or course. After creating the template, it is important to form a competency assessment scale and give it a proper name. The degree of competence for each task can be determined by a level scale, by defining levels (high, medium and sufficient) or by a point scale. After developing a competency assessment scale, competencies and their components should be coded. The competencies can be coded according to the principle of the first letters, and the components of each competency can be numbered in Arabic numerals (Fig. 2).

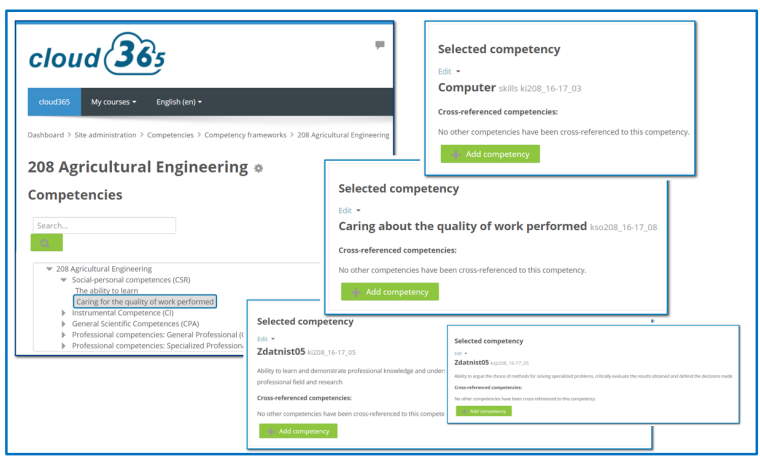

Figure 2 General view of the repository of competencies of the digital media communication environment with components.

After the repository of competencies was filled, they should be added to each digital educational training course. Each task should be considered and submitted in such a way that it promotes a comprehensive system of competencies. Setting up the process of acquiring competencies and their components based on the set of tasks is a link to the sequence of completion of certain tasks. One competency, or its component, is essentially the totality of the results of the tasks to which it is attached.

A topical aspect is the monitoring of the system of acquisition of competencies by the higher education applicants in the conditions of digital space. Monitoring is the continuous reviewing of the state of the acquisition of professional competencies in order to prevent unwanted deviations by the most important parameters in the process of preparation of Bachelors in the digital space of higher education institution. Monitoring is carried out through a set of methods and clearly developed procedures [29]. After completing the task according to the training scale, the degree of acquisition of competence attached to the task is indicated.

Upon completion of the tasks, it is possible to get a holistic picture of the competencies acquired as a result of training in all courses provided by the educational program. In fact, this is the arithmetic mean of the total percentage of competencies acquired through training courses in digital education space.

\section{METHODS}

The experiment involved 204 Bachelors in specialty 'Electric Power, Electrical Engineering and Electrical Mechanics', 65 from the first year (31.86\%), 
61 from the second $(29.90 \%), 40$ from the third $(19.61 \%)$ and 38 from the fourth (18.63\%). Respondents are higher education applicants at the Mykolayiv National Agrarian University in Ukraine. The Cloud365 digital platform (https://cloud365.org.ua/) is built on state-of-the-art and time-tested technologies for the development of websites, applications and information systems. The development of such a platform is based on competent and valid code in HTML, CSS and JavaScript, providing the minimum size of web pages and high speed of applications, provides adaptability of pages to different sizes of screens of computers and mobile devices and backward compatibility with old versions of browsers. As a result, such a platform always receives positive ratings from Google services, which facilitates their promotion in search engine ranking.

Descriptive statistical measures were used to verify the validity of the results of the session control using the Kolmogorov-Smirnov statistical criterion before and after the experiment in the experimental and control groups [30]. Before the experimental work, the respondents were divided into experimental (103 higher education applicants) and control groups (101 higher education applicants). We formulate statistical hypotheses to test the appropriate level of competencies acquisition by Bachelors in specialty 'Electric Power, Electrical Engineering and Electrical Mechanics' in the conditions of the digital media communication environment.

$\mathrm{H}_{0}$ : the number of higher education applicants in specialty 'Electric Power, Electrical Engineering and Electrical Mechanics' whose corresponding level before the experiment is no higher in the experimental group than in the control group.

$\mathrm{H}_{1}$ : the number of higher education applicants in specialty 'Electric Power, Electrical Engineering and Electrical Mechanics', in which the corresponding level before the experiment in the experimental group is higher than in the control group.

$N_{i}=\frac{n_{i}}{n_{1}+n_{2}+n_{3}+n_{4}}$

$N_{i}$ - the ratio of the number of respondents of the relevant level to the total number in the experimental groups.

$N_{i}^{*}=\frac{n_{i^{*}}}{n_{1^{*}+n_{2^{*}}+n_{3^{*}+n_{4^{*}}}}}$

$N_{i}{ }^{*}$ - the ratio of the number of respondents of the appropriate level to the total number (as a percentage) in the control groups.

\section{RESEARCH RESULTS}

We can check the reliability of the results of the session control using the Kolmogorov-Smirnov statistical criterion at the end of the experiment in the experimental and control groups before the experiment.

It is determined $d_{\max }=0.02$ and the level at which this value falls, and calculated the value of $\lambda$ by the equation (3):

$$
\begin{gathered}
\lambda_{\text {emp. }}=d_{\text {max }} \sqrt{\frac{f_{\text {exp }} \cdot f_{\text {contr }}}{f_{\text {exp }}+f_{\text {contr }}}}==0,02 \sqrt{\frac{569 \cdot 564}{569+564}}= \\
=0,02 \cdot 16,8298687=0,336597374 \approx 0,3 \\
\lambda_{\text {crit }}=\left\{\begin{array}{l}
\lambda_{0,05}=1,36 \\
\lambda_{0,01}=1,63
\end{array}\right.
\end{gathered}
$$

$f_{\text {exp. }}-$ the number of respondents in the experimental group; $f_{\text {contr. }}$ - number of respondents in the control group.

The reliability of the obtained results is verified using the calculation table (Table 1).

\begin{tabular}{|c|c|c|c|c|c|c|c|}
\hline \multirow{2}{*}{ త্ } & \multicolumn{2}{|c|}{$\begin{array}{l}\text { Empirical } \\
\text { frequencies }\end{array}$} & \multicolumn{2}{|c|}{$\begin{array}{l}\text { Empirical } \\
\text { shares }\end{array}$} & \multicolumn{2}{|c|}{$\begin{array}{l}\text { Accumula- } \\
\text { ted empiri- } \\
\text { cal shares }\end{array}$} & \multirow{2}{*}{$\begin{array}{l}\text { Difference } \\
d=\left|N_{i}-N_{i}^{*}\right|\end{array}$} \\
\hline & $f_{\text {exp. }}$ & $f_{\text {contr. }}$ & $\begin{array}{l}f_{\text {exp. }}^{*} \\
(\%)\end{array}$ & $\begin{array}{c}f_{\text {contr }}^{*} \\
(\%)\end{array}$ & $N_{i}$ & $N *_{i}$ & \\
\hline $\mathbf{A}$ & 12 & 14 & 11,65 & 13,86 & 0,12 & 0,14 & $-0,02$ \\
\hline BC & 29 & 28 & 28,16 & 27,7, & 0,28 & 0,28 & 0,00 \\
\hline DE & 56 & 55 & 54,37 & 54,46 & 0,54 & 0,54 & 0,00 \\
\hline FX & 6 & 4 & 5,83 & 3,96 & 0,06 & 0,04 & 0,02 \\
\hline Sum & 103 & 101 & 100 & 100 & & & \\
\hline
\end{tabular}

Table 1. Calculation of $\lambda$-criterion of the KolmogorovSmirnov to compare levels before the experiment.

The empirical value is in the zone of insignificance, taking into account the critical level for comparing the level after the experiment. So, $\lambda_{\text {emp. }}<\lambda_{\text {contr }} \mathrm{H}_{1}-$ rejects, the hypothesis $\mathrm{H}_{0}$ remains. The number of higher education applicants in specialty 'Electric Power, Electrical Engineering and Electrical Mechanics' in which the corresponding level before the experiment in the experimental group is not higher than in the control group.

It is determined $d_{\max }=0.19$ and the level at which this value falls, and calculated the value of $\lambda$ by the equation (4):

$\lambda_{\text {emp }}=d_{\text {max }} \sqrt{\frac{f_{\text {exp }} \cdot f_{\text {contr }}}{f_{\text {exp }}+f_{\text {contr }}}}=0,19 \sqrt{\frac{569 \cdot 564}{569+564}}=$

$=0,19 \cdot 16,8298687=3,197675053 \approx 3,2$

The reliability of the obtained results is performed using the criterion $\lambda$ of Kolmogorov-Smirnov to 
compare the levels after the experiment and verified using the calculation table (Table 2).

Table 2. Calculation of the $\lambda$-criterion of KolmogorovSmirnov to compare the levels after the experiment.

\begin{tabular}{|c|c|c|c|c|c|c|c|}
\hline \multirow{2}{*}{ ᄅ্] } & \multicolumn{2}{|c|}{$\begin{array}{l}\text { Empirical } \\
\text { frequencies }\end{array}$} & \multicolumn{2}{|c|}{$\begin{array}{c}\text { Empirical } \\
\text { shares }\end{array}$} & \multicolumn{2}{|c|}{$\begin{array}{c}\text { Accumulated } \\
\text { empirical } \\
\text { shares }\end{array}$} & \multirow{2}{*}{\begin{tabular}{|l} 
Difference \\
$d=\mid N_{i}-N^{*}$
\end{tabular} \mid} \\
\hline & $f_{\text {exp. }}$ & $f_{\text {contr. }}$ & $\begin{array}{l}f_{\text {exp }}^{*} \\
(\%)\end{array}$ & $\begin{array}{l}f_{\text {"contr }}^{*} \\
(\%)\end{array}$ & $N_{i}$ & $\boldsymbol{N}^{*}{ }_{i}$ & \\
\hline $\mathbf{A}$ & 11 & 21 & 10,68 & 20,79 & 0,11 & 0,21 & 0,10 \\
\hline BC & 30 & 42 & 29,13 & 41,58 & 0,29 & 0,42 & 0,12 \\
\hline DE & 57 & 37 & 55,34 & 36,63 & 0,55 & 0,37 & 0,19 \\
\hline FX & 5 & 1 & 4,85 & \begin{tabular}{|l|}
0,99 \\
\end{tabular} & 0,05 & 0,01 & 0,04 \\
\hline Sum & 103 & 101 & 100 & 100 & & & \\
\hline
\end{tabular}

The empirical value is in the zone of significance, taking into account the critical level for comparing the level after the experiment. So, $\lambda_{\text {emp. }}<\lambda_{\text {contr }}$. $\mathrm{H}_{0}-$ rejects, the hypothesis $\mathrm{H}_{1}$ remains. The number of Bachelors in the field of Electrical Engineering in which the corresponding level before the experiment in the experimental group is higher than in the control group.

\section{CONCLUSION}

Thus, the application of technology of competencies acquisition by Bachelors in higher education institutions in the conditions of the digital media communication environment increases the opportunities for quality training. In order to improve the preparation of Bachelors in the higher education institutions, it is advisable to develop an electronic curriculum in the digital space, digital repositories and educational courses. Considerable attention should be paid to the development of educational content and tasks that are able to form professional competencies and its monitoring. The acquisition of professional competencies by Bachelors in the higher education institutions can be accomplished through digital media communication technology. The technology of the proposed digital space Cloud 365 is able to evaluate the degree of competence and academic achievement based on the integration of LMS + Office 365 , sets a fundamentally different logic for organizing the educational process, the logic of setting and solving problems, not only individual but also group and team character. Realization of digital media communication technology of acquisition of professional competencies of Bachelors in the higher education institutions is based on creation of repository of professional competencies in digital space Cloud365, linking of the educational competencies, laid in the repository of professional competencies, to the tasks in the digital educational environment, monitoring the acquisition of professional competencies by higher education applicants. In the process of completing the task, higher education applicants and tutors have the opportunity to monitor the degree of acquisition of certain competencies, and at the end of training to evaluate the holistic picture of the competences acquired as a result of training in all courses provided by the educational program.

\section{REFERENCES}

[1] Law of Ukraine On higher education, 2020, http://zakon4.rada.gov.ua/laws/show/1556-18

[2] Tuning educational structures in Europe. TUNING (for acquaintance with special (professional) competences and examples of standards,

2013,

http://www.unideusto.org/tuningeu/

[3] UNESCO, UNESCO Competency Framework, 2016,

https://unesdoc.unesco.org/ark:/48223/pf000024 5056

[4] European Commission, Competency Framework, 2016,

https://ec.europa.eu/regional_policy/en/policy/h ow/improving-investment/competency/

[5] Council of Europe, Reference Framework of Competences for Democratic Culture, 2020, https://www.coe.int/en/web/campaign-free-tospeak-safe-to-learn/reference-framework-ofcompetences-for-democratic-culture

[6] I. Blau, T. Shamir-Inbal, O. Avdiel, How does the pedagogical design of a technology-enhanced collaborative academic course promote digital literacies, self-regulation, and perceived learning of students?, The Internet and Higher Education $45 \quad(2020) \quad 100722 . \quad$ DOI: https://doi.org/10.1016/j.iheduc.2019.100722

[7] I. Grosemans, L. Coertjens, E. Kyndt, Exploring learning and fit in the transition from higher education to the labour market: A systematic review, Educational Research Review 21 (2017) 67-84.

DOI: https://doi.org/10.1016/j.edurev.2017.03.001

[8] S. Schneider, M. Beege, S. Nebel, G. D. Rey, A meta-analysis of how signaling affects learning with media, Educational Research Review 23 (2018) 1-24. DOI: https://doi.org/10.1016/j.edurev.2017.11.001 
[9] S. Manca, Snapping, pinning, liking or texting: Investigating social media in higher education beyond Facebook, The Internet and Higher Education 44 (2020) 100707. DOI: https://doi.org/10.1016/j.iheduc.2019.100707

[10] O. Kuzminska, M. Mazorchuk, N. Morze, O. Kobylin, Attitude to the digital learning environment in Ukrainian Universities, CEUR Workshop Proceedings 2393 (2019) 53-67. http://ceur-ws.org/Vol-2393/paper_245.pdf

[11] M. Plenkovic, D. Mustic, Media communication and cultural hybridization of digital society, Media, culture and public relations 11 (2020) 151-160.

DOI: https://doi.org/10.32914/mcpr.11.2.3.

[12] K. Baranidharan, K. Saravanan, A study on digital media communication, International Journal of Pure and Applied Mathematics 119 (2018) 14199-14208.

[13] J. Strijbos, N. Engels, K. Struyven, Criteria and standards of generic competences at bachelor degree level: A review study, Educational Research Review 14 (2015) 18-32. DOI: https://doi.org/10.1016/j.edurev.2015.01.001

[14] A-E. Guerrero-Roldán, I. Noguera, A model for aligning assessment with competences and learning activities in online courses, The Internet and Higher Education 38 (2018) 36-46. DOI: https://doi.org/10.1016/j.iheduc.2018.04.005

[15] Y. Chua, Z. Don, Effects of computer-based educational achievement test on test performance and test takers' motivation, Computers in Human Behavior 29 (2013) 1889-1895. DOI: https://doi.org/10.1016/j.chb.2013.03.008

[16] I. Arnold, Cheating at online formative tests: Does it pay off?, The Internet and Higher Education 29 (2016) 98-106. DOI: https://doi.org/10.1016/j.iheduc.2016.02.001

[17] J. Portilla, A. Varona, N. Otegi, Making Explicit and Reinforcing Horizontal Competences in an Electronic Engineering Degree, Procedia - Social and Behavioral Sciences 141 (2014) 961-968. DOI: https://doi.org/10.1016/j.sbspro.2014.05.165

[18] S. Molinillo, R. Anaya-Sánchez, R. AguilarIllescas, M. Vallespín-Arán, Social media-based collaborative learning: Exploring antecedents of attitude, The Internet and Higher Education 38
(2018) 18-27. DOI: https://doi.org/10.1016/j.iheduc.2018.04.003

[19] D.C. DeAndrea, N.B. Ellison, R. LaRose, C. Steinfield, A. Fiore, Serious social media: On the use of social media for improving students' adjustment to college, The Internet and Higher Education 15 (2012) 15-23. DOI: https://doi.org/10.1016/j.iheduc.2011.05.009

[20] D. Westerman, E.S. Daniel, N.D. Bowman, Learned risks and experienced rewards: Exploring the potential sources of students' attitudes toward social media and face-to-face communication, The Internet and Higher Education 31 (2016) 52-57. DOI: https://doi.org/10.1016/j.iheduc.2016.06.004

[21] M. Gawrycka, J. Kujawska, M. Tomchak, Selfassessment of competencies of students and graduates participating in didactic projects - Case study, International Review of Economics Education 36 (2020) 100204. DOI: https://doi.org/10.1016/j.iree.2020.100204

[22] S. Manca, M. Ranieri, "Yes for sharing, no for teaching!": Social Media in academic practices, The Internet and Higher Education 29 (2016) 6374.

DOI: https://doi.org/10.1016/j.iheduc.2015.12.004

[23] J. Waycott, C. Thompson, J. Sheard, R. Clerehan, A virtual panopticon in the community of practice: Students' experiences of being visible on social media, The Internet and Higher Education 35 (2017) 12-20. DOI: https://doi.org/10.1016/j.iheduc.2017.07.001

[24] V. Oliynik, O. Samoylenko, I. Batsurovska, N. Dotsenko, Formation of future agricultural engineers professional competences in computeroriented environment of higher education institutions, Informational Technologies and Learning Tools 68 (2018) 140-154. DOI: https://doi.org/10.33407/itlt.v68i6.2525

[25] S. Manca, S. Bocconi, B. Gleason, "Think globally, act locally": A global approach to the development of social media literacy, Computers \& Education 160 (2021) 104025. DOI: https://doi.org/10.1016/j.compedu.2020.104025

[26]B. Cho, Y. Baek, Exploring factors of media characteristic influencing flow in learning through virtual worlds, Computers \& Education 57 (2011) 2382-2394. DOI: https://doi.org/10.1016/j.compedu.2011.06.019 
[27] European Commission, Digital Learning \& ICT in Education, https://ec.europa.eu/digital-singlemarket/en/digital-learning-ict-education

[28] European Union Framework Program, Council Recommendation of 22 May 2018 on key competences for lifelong learning, Official Journal of the European Union, C 189/01 (2018). https://eur-lex.europa.eu/legalcontent/EN/TXT/PDF/?uri=CELEX:32018H060 $4(01) \&$ from $=$ LT

[29] D. Babenko, I. Batsurovska, N. Dotsenko, O. Gorbenko, I. Andriushenko, N. Kim, Application of monitoring of the informational and educational environment in the engineering education system, in: 2019 IEEE International Conference on Modern Electrical and Energy Systems (MEES), Kremenchuk, Ukraine, 2019. DOI:

https://doi.org/10.1109/MEES.2019.8896469

[30] A. Kolmogorov, Sulla determinazione empirica di una legge di distribuzione, Giornale dell'Istituto Italiano degli Attuari 4 (1933) 83-91. 